\title{
The cost of stroke in private hospitals in Brazil: a one-year prospective study
}

\author{
0 custo do AVC em hospitais privados no Brasil: um estudo prospectivo
}

Luana Gabriela Dalla Rosa VIEIRA, ${ }^{1}$ Juliana SAFANELLI1,2, Tainá de ARAUJO', Helen Aparecida SCHUCH², Maria Helena Ribeiro KUHLHOFF², Vivian NAGEL ${ }^{2}$, Adriana Bastos CONFORTO ${ }^{3,4}$, Gisele Sampaio SILVA ${ }^{3,4}$, Suleimy MAZIN ${ }^{5}$, Norberto Luiz CABRAL ${ }^{1,2}$

\begin{abstract}
Few studies from low- and middle-income countries have assessed stroke and cerebral reperfusion costs from the private sector. Objective: To measure the in-hospital costs of ischemic stroke (IS), with and without cerebral reperfusion, primary intracerebral hemorrhage (PIH), subarachnoid hemorrhage (SAH) and transient ischemic attacks (TIA) in two private hospitals in Joinville, Brazil. Methods: Prospective disease-cost study. All medical and nonmedical costs for patients admitted with any stroke type or TIA were consecutively determined in 2016-17. All costs were adjusted to the gross domestic product deflator index and purchasing power parity. Results: We included 173 patients. The median cost per patient was US\$3,827 (IQR: 2,800-8,664) for the 131 IS patients; US \$2,315 (IQR: 1,692-2,959) for the 27 TIA patients; US\$16,442 (IQR: 5,108-33,355) for the 11 PIH patients and US\$28,928 (IQR: 12,424-48,037) for the four SAH patients ( $p<0.00001)$. For the six IS patients who underwent intravenous thrombolysis, the median cost per patient was US $\$ 11,463$ (IQR: 8,931-14,291), and for the four IS patients who underwent intra-arterial thrombectomy, the median cost per patient was US $\$ 35,092$ (IQR: 31,833-37,626; $p<0.0001)$. A direct correlation was found between cost and length of stay $(r=0.67, p<0.001)$. Conclusions: Stroke is a costly disease. In the private sector, the costs of cerebral reperfusion for IS treatment were three-to-ten times higher than for usual treatments. Therefore, cost-effectiveness studies are urgently needed in low- and middle-income countries.
\end{abstract}

Keywords: Stroke; costs and cost analysis; hospitals.

\section{RESUMO}

Poucos estudos determinam o custo do AVC em países de baixa e média renda nos setores privados. Objetivos: Mensurar o custo hospitalar do tratamento do(a): AVC isquêmico com e sem reperfusão cerebral, hemorragia intracerebral primária (HIP), hemorragia subaracnóidea e ataque isquêmico transitório (AIT) em hospitais privados de Joinville, Brasil. Métodos: Estudo prospectivo de custo de doença. Os custos médicos e não médicos dos pacientes admitidos com qualquer tipo de AVC ou AIT foram consecutivamente verificados em 2016-17. Os valores foram ajustados ao índice do deflator do produto interno bruto e à paridade do poder de compra. Resultados: Nós incluímos 173 pacientes. A mediana de custo por paciente foi de US\$3.827 (IQR: 2.800-8.664) para os 131 pacientes com AVC isquêmico; US\$2.315 (1.692-2.959) para os 27 pacientes com AIT; US\$ 16.442 (5.108-33.355) para os 11 pacientes com HIP e US\$ 28.928 (12.424-48.037) para os quatro pacientes com HSA ( $p<0,00001$ ). Para seis pacientes submetidos à trombólise intravenosa, a mediana do custo por paciente foi de US\$11.463 (8.931-14.291) e, para quatro pacientes submetidos à trombectomia intra-arterial, a mediana de custo por paciente foi de US\$35.092 (31.833-37.626; p < 0,0001). Uma correlação direta foi encontrada entre custo e tempo de permanência ( $r=0,67, p<0,001)$. Conclusão: 0 AVC é uma doença cara. Em ambiente privado, os custos da reperfusão cerebral foram de três a dez vezes superiores aos tratamentos habituais do AVC isquêmico. Portanto, estudos de custo-efetividade são urgentemente necessários em países de baixa e média rendas.

Palavras-chave:Acidente vascular cerebral; custo e análise de custo; hospitais.

\footnotetext{
Universidade da Região de Joinville, Joinville, SC, Brasil;

${ }^{2}$ Registro de AVC de Joinville, Joinville, SC, Brasil;

${ }^{3}$ Universidade de São Paulo, Divisão de Clínica Neurológica, São Paulo, SP, Brasil;

${ }^{4}$ Hospital Israelita Albert Einstein, São Paulo, SP, Brasil;

${ }^{5}$ Universidade de São Paulo, Faculdade de Medicina de Ribeirão Preto, Ribeirão Preto, SP, Brasil.

Luana Gabriela Dalla Rosa Vieira (iD) https://orcid.org/0000-0003-4317-6914; Juliana Safanelli (iD https://orcid.org/0000-0003-1924-8279; Tainá de Araujo (iD https://orcid.org/0000-0001-6558-5415; Helen Aparecida Schuch (ID) https://orcid.org/0000-0001-7025-2754; Maria Helena Ribeiro Kuhlhoff (iD https://orcid.org/0000-0003-1384-9444; Vivian Nagel (iD) https://orcid.org/0000-0002-3321-6110; Adriana Bastos Conforto (iD) https://orcid. org/0000-0001-7869-3490; Gisele Sampaio Silva (iD) https://orcid.org/0000-0002-3247-3123; Suleimy Mazin (iD https://orcid.org/0000-0001-61217295; Norberto Luiz Cabral iD https://orcid.org/0000-0001-5829-9699
}

Correspondence: Luana G. D. R. Vieira; Universidade da Região de Joinville; Rua Paulo Malschitzki, 10; 89219-710 Joinville SC, Brasil; E-mail: luanagdr@yahoo.com.br Support: This study was supported by the National Council for Scientific and Technological Development, CNPq Grant 402396/2013-8.

Conflict of interest: There is no conflict of interest to declare.

Received 20 August 2018; Received in final form 22 January 2019; Accepted 12 February 2019. 
Stroke costs are predicted to rise in low- and middleincome countries ${ }^{1,2}$. This forecast is based on the increase in prevalence rates and the costs of new cerebral reperfusion interventions for the treatment of ischemic stroke (IS) ${ }^{1,2}$. Despite most strokes occurring in low- and middle-income countries, there is limited information about the costs of stroke treatments in these settings ${ }^{3}$. For instance, only one retrospective study has reported the public costs of stroke in Brazil $^{4}$, and this was conducted before IS cerebral reperfusion treatment was available.

The incidence of all strokes decreased by $37 \%$ in Joinville from 1995 to 2013; however, the one-year prevalence of functional dependency from 2005-2006 $(n=759)$ to 2012-2013 ( $n=922$ ) showed a nonsignificant increase of $32 \%$ for IS and a nonsignificant increase of $66 \%$ for primary intracerebral hemorrhage $(\mathrm{PIH})^{5}$.

After 2014, the results of interventional studies showed that cerebral reperfusion for IS opened up new perspectives for IS prognosis ${ }^{6}$. In Brazil, the state-run health care system is universal. Three quarters of the population use it exclusively and one quarter uses both public and private health services ${ }^{7}$. However, the costs of these treatment options from the private sector in low- and middle-income countries, where health budgets are tight, remains unknown. We aimed to measure private in-hospital costs of IS (with and without cerebral reperfusion), primary intracerebral hemorrhage (PIH), subarachnoid hemorrhage (SAH) and transient ischemic attack (TIA) in Joinville, Brazil.

\section{METHODS}

\section{Study design}

This was a prospective bottom-up, one-year prevalencebased cost-of-illness study ${ }^{8}$. Data were extracted from two private hospitals (neither hospital has a stroke or neurocritical care unit), in the city of Joinville, Brazil, from September 1, 2016 to August 30, 2017. We included first-ever or recurrent IS, PIH, SAH or TIA in patients who were aged $\geq 18$ years old, consecutively admitted over the study period. Patients were excluded if they had incomplete medical records, if they had been transferred from another hospital or if their hospitalization time exceeded the deadline for data collection.

\section{Data collection}

The principal investigator (LGDRV) used a questionnaire (Figure 1) to register all checklist items from admission until hospital discharge in each patient. Admission date, final stroke diagnosis, hospitalization units, diagnostic work-up, medication, equipment, medical rounds, medical and nursing procedures, types of food, multidisciplinary rehabilitation sessions and clinical complications were extracted from the patient's medical records. Demographic information, socioeconomic status, cardiovascular risk factors and 30-day functional outcomes were extracted from the Joinville Stroke Registry $^{5}$. The routine for stroke investigation followed the guidelines issued by the Brazilian Society of Cerebrovascular Diseases $^{9,10,11}$ (Table 1). The severity of IS was stratified according to the National Institute of Health Stroke Scale (NIHSS), with $0-3$ being minor, $4-10$ being moderate and 10 being severe ${ }^{12}$.

\section{Data analysis}

Collected data were compared with the patient's final hospital bill. The findings were discussed with the hospital's management centre if any divergence was identified. Together, the two hospitals serve 27 health plans, each with differences in their costs and fees criteria. Both hospitals use a mixture of methods to compute costs, which results in methodological differences in the allocation of costs (Figure 2).

Therefore, to equate the methodological differences, the medical and nonmedical costs were split into 12 distinct subitems: 1) hospital daily: all hospital services including nursing services, private or semiprivate rooms, nutritionists, psychologists, pharmacy and kitchen staff, electrical power and water consumption, garbage collection, depreciation of equipment, cleaning and laundry; 2) emergency room rate: salaries of emergency room personnel, laundry, maintenance of equipment, electricity and water; 3) medical visits: daily medical and on-call visits; 4) medical procedures: material costs, medical fees and operating room fees, including all staff wages, electricity, water, maintenance and equipment depreciation; 5) rehabilitation team: daily visits from speech therapists, physiotherapists and occupational therapists; 6) equipment for procedures: needles, syringes, gauze, suction probes etc.; 7) medications: drugs and intravenous (IV) solutions; 8) laboratory tests: wages (biochemists, technicians and administrative assistants), tests, electric power, water, equipment maintenance and depreciation; 9) diagnostic work-up sections: medical reports and technical staff, materials, electric power, water, equipment maintenance and depreciation; 10) special feeding: enteral diet and special supplements (which are calculated separately from the hospital daily costs), unit value of the diet per bottle and supplement used and materials and equipment for administration; 11) medical gases: daily rate of gas consumption and 12) administrative fees: wages and uniforms of clerks, security staff, computer teams, receptionists and other administrative departments.

All personnel wages included the wage itself plus social and labor charges. Nonmedical costs were obtained by apportionment; for instance, the cost of employee labor was the sum of the average annual labor, the costs of training and uniforms divided by the number of sector beds. These apportions were present when calculating the fraction of electric power consumption, maintenance and depreciation of equipment in all sectors, as well as when calculating the cost of labor (wages) 


\begin{tabular}{|c|c|c|c|}
\hline MEDICAL CARE & (1) yes (0) no & MEDICAL PROCEDURES & $(1)$ yes $(0)$ no \\
\hline Neurologist & & Central venous catheter & \\
\hline General physician & & Orotracheal intubation & \\
\hline Other: & & Lumbar puncture & \\
\hline General physician & & Surgical debridement & \\
\hline General surgeon & & Hemodynamic & \\
\hline Neurosurgeon & & Surgery (what?) & \\
\hline Intensive care physician & & Other? & \\
\hline Another physician & & Other? & \\
\hline Other? & & Other? & \\
\hline Other? & & Other? & \\
\hline \multicolumn{4}{|l|}{ Other? } \\
\hline PROCEDURES OF THE NURSING TECHNICIAN & (1) yes (0) no & NURSING PROCEDURES & (1) yes (0) no \\
\hline Venous puncture & & Urinary Catheterisation (relief) & \\
\hline Application of injectables: IV, IM , ID , SC & & Urinary Catheterisation (late) & \\
\hline Orotracheal aspiration & & Naso/orogastric intubation & \\
\hline Oral aspiration & & Naso/oroenteral intubation & \\
\hline Common bandaged & & Orotracheal aspiration & \\
\hline Special bandaged:-_-_-_-_-_-_- & & Caregiver guidance & \\
\hline Other? & & Other? & \\
\hline Other? & & Other? & \\
\hline Other?_-_-_-_-_-_-_-_-_-_- & & Other? _--_-_-_-_-_-_-_-_-_ & \\
\hline MULTIDISCIPLINARYTEAM & (1) yes (0) no & SURGERY CENTER & (1) yes (0) no \\
\hline Nutritionist & & Technical in hemodynamics & \\
\hline Physical therapy & & Neurosurgeon & \\
\hline Occupational therapy & & General surgeon & \\
\hline Psychotherapy & & Anaesthesiologist & \\
\hline Attendant social & & Nursing technician & \\
\hline Speech therapy & & Nurse & \\
\hline Pharmaceutical & & Radiology technician & \\
\hline Pharmacy dispenser & & Other? & \\
\hline Other? & & Other? & \\
\hline LABORATORY TESTS & (1) yes (0) no & COMPLEMENTARY EXAMS & (1) yes (0) no \\
\hline Blood count & & X-ray (thorax AP) & \\
\hline Potassium & & X-ray (thorax P) & \\
\hline Sodium & & X-ray (abdomen) & \\
\hline Coagulogram & & Deglutogram & \\
\hline C-reactive protein & & Carotid ultrasound & \\
\hline Cholesterol & & Transcranial Doppler & \\
\hline Triglycerides & & Transthoracic echocardiography & \\
\hline Blood glucose & & Transoesophageal echocardiography & \\
\hline Blood culture & & Holter (24 hours) & \\
\hline Urea & & Electrocardiogram & \\
\hline Creatinine & & $\begin{array}{l}\text { Cranial computed tomography (without } \\
\text { contrast) }\end{array}$ & \\
\hline Urinalysis & & Cranial computed tomography (with contrast) & \\
\hline
\end{tabular}

Figure 1. Data collection questionnaire: checklist. 
Continuation

Hepatic transaminases

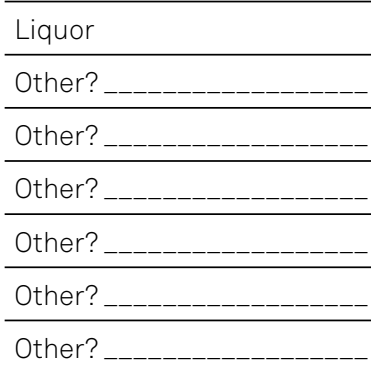

TYPE OF NUTRITION

Enteral nutrition

Parenteral nutrition

Food thickener

Conventional nutrition (patient)

Conventional nutrition (patient's companion)

Hyperproteic nutrition

Hypercaloric nutrition

Other?

Other? ------------------

(1) yes (0) no ----_-_ml/24h ------_ml/24h ---_--_-_ $/ 24 h$

(2)

POSOLOGY
Cranial magnetic resonance (without contrast)

Cranial magnetic resonance (with contrast)

Cerebral angioresonance

Cerebral angiography

Outsourced exam

Other?

Other?

Other?

MEDICAL AND HOSPITAL MATERIALS

(1)yes (0) no

Gastric catheter

Enteral catheter

Urinary catheter (relief)

Urinary catheter (late)

Aspiration catheter

Urine collection bag

Colostomy bag

Common bandaged

Special bandaged (what?)

Dersani oil

Bath oil

Clorexidine

Povidine

Geriatric diapers (number

per day)

Aspiration bottle

Latex

Oxygen

Oxygen mask

Oxygen catheter

Orotracheal tube

Mechanical ventilation

Oximeter

Tape for blood glucotest (number

per day)

Blood glucotest apparatus

Surgical material_-_-_-_-_-_-

Pyramidal mattress

Triangle of positioning

Other?

Other?

Other?

Other?

Other? 


\begin{tabular}{|c|c|}
\hline Stroke type & Protocol for acute stroke evaluation \\
\hline \multirow{8}{*}{ IS or TIA } & Cranial CT or MRI \\
\hline & Carotid and vertebral ultrasound \\
\hline & Electrocardiogram \\
\hline & Chest X-ray \\
\hline & Transthoracic or transesophageal echocardiography \\
\hline & Transcranial doppler \\
\hline & $\begin{array}{l}\text { Biochemical exams: blood count, blood glucose, creatinine, urea, electrolytes, arterial gasometry, } \\
\text { coagulogram, total cholesterol and fractions, triglycerides, fibrinogen, test for syphilis. }\end{array}$ \\
\hline & $\begin{array}{c}\text { In young adults or undefined etiology: laboratory evaluation for autoimmune diseases, arteritis, coagulation } \\
\text { disorders, genetic profile, homocysteine. }\end{array}$ \\
\hline \multirow{5}{*}{$\mathrm{PIH}$} & Cranial CT or MRI \\
\hline & Cerebral CT or MRI angiography when undefined etiology \\
\hline & Chest X-ray \\
\hline & Electrocardiogram \\
\hline & $\begin{array}{c}\text { Biochemical exams: blood count, blood glucose, creatinine, urea, electrolytes, arterial gasometry, } \\
\text { coagulogram. }\end{array}$ \\
\hline \multirow{6}{*}{ SAH } & Cranial CT or MRI \\
\hline & Lumbar puncture when negative neuroimaging \\
\hline & Chest X-ray \\
\hline & Electrocardiogram \\
\hline & Cerebral CT or MRI angiography when undefined etiology \\
\hline & $\begin{array}{c}\text { Biochemical exams: blood count, blood glucose, creatinine, urea, electrolytes, arterial gasometry, } \\
\text { coagulogram. }\end{array}$ \\
\hline
\end{tabular}

\section{Meetings with hospital managers for the construction of cost blocks}

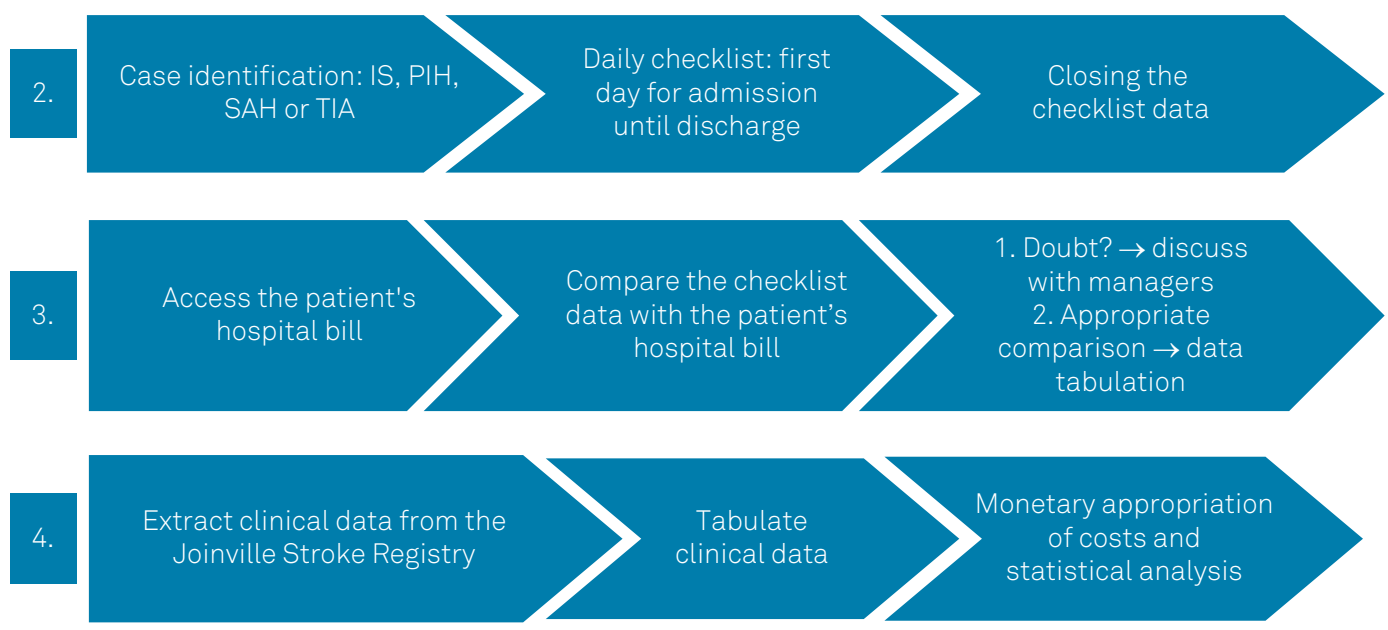

IS: ischemic stroke; PIH: primary intracerebral hemorrhage; $\mathrm{AAH}$ : subarachnoid hemorrhage; TIA: transient ischemic attack.

Figure 2. Methodology flowchart.

for the hospital inpatient stay (e.g. the nursing team, nutritionists, pharmacists and psychologists), laboratory tests (e.g. biochemical and other employees in this sector), diagnostic work-up sections (e.g. technical staff); administrative fees (e.g. the administrative, security and janitorial teams) and rehabilitation (e.g. in the case of professionals employed by the hospital, excluding outsourced services).

We determined the unit costs as the mean cost of each item per patient in the hospital stay and diagnostic work-up, including medical and nonmedical items. 


\section{Statistical analysis}

We evaluated differences among patient subgroups by using a $\chi^{2}$ test, $t$ test, or Mann-Whitney $U$ test as appropriate. All tests were two tailed. Cost data were converted to 2016 currency values using a web-based tool (CCEMG EPPI-Centre Cost Converter $)^{13}$. The cost was first converted into the current year cost for Brazil using the gross domestic product (GDP) deflator index. In the next step, this cost was converted into United States dollars (US\$) (for 2016) using conversion rates based on purchasing power parity (PPP) for the GDP (the Brazilian real PPP value for 2016 was 0.49$)^{13}$. For comparison, the original costs of other studies were converted to 2016 values. All values were in US\$. Tests were performed using Statistical Analysis System software (version 9.2) with PROC GENMOD (SAS Institute, Inc, Cary, NC). The study was approved by the ethics in research committees at the involved hospitals and the UNIVILLE-Joinville Region University (opinion number: 1.657.067).

\section{RESULTS}

A total of 173 patients were included in the study, of whom $76 \%$ (131/173) were diagnosed with IS, 6\% (11/173) with PIH, 2\% (4/173) with SAH and $16 \%$ (27/173) with a TIA. We excluded 11 patients who were transferred from other hospitals. The overall mean age of the cohort was 68 years (SD \pm 15 ). The median NIHSS scores for IS were 2 (IQR: $1-5$ ), for PIH were 5 (IQR: 4-12) and for SAH were 8 (IQR: 7-12). Of the 131 IS patients, $62 \%$ (81) had mild stroke (NIHSS:
0-3), $27 \%$ (35) had a moderate stroke (NIHSS: 4-10) and 11\% (15) had a severe stroke (NIHSS: >10). The mean length of stay (LOS) for IS was 8 days (SD \pm 7 ), for PIH was 15 days $(\mathrm{SD} \pm 16)$, for $\mathrm{SAH}$ was 11 days (SD \pm 5 ) and for TIA was 4 days (SD \pm 2 ). The 30-day case-fatality rates were $36 \%$ (4/11) for $\mathrm{PIH}$ patients and 6\% (8/131) for IS patients. There were no deaths in the TIA and SAH groups.

The median total cost of hospitalization per patient based on stroke type ranged from US\$2,316 (IQR: 1,692-2,959) for TIA to US\$28,928 (IQR: 12,424-48,037) for SAH patients $(\mathrm{p}<0.0001)$. Table 2 shows the total in-hospital costs and the daily costs among all stroke types and TIA. The median and mean costs of seven cardioembolic IS due to atrial fibrillation were US\$6,386 (IQR: 4,003-10,589) and US\$9,505 (SD $\pm 7,612$ ), respectively.

The following patients were admitted in the intensive care unit (ICU): $31 / 131$ patients with IS, $8 / 11$ patients with $\mathrm{PIH}, 4 / 4$ patients with SAH and $1 / 27$ patient with TIA (this patient was submitted to electrical cardioversion for atrial fibrillation). In patients with IS, those who stayed in ICU remained twice as long in hospital and had a mean cost six times higher than those who did not go to the ICU. For PIH patients, the mean cost was twice as high in patients who stayed in the ICU with similar LOS.

As expected, the cost of hospitalization increased with LOS. For IS, the median cost for up to seven days was US\$2,639 (IQR: 2,017-3,274), which increased to US $\$ 4,743$ (IQR: 3,609-8,687) for 7-14 days and US $\$ 29,499$ (IQR: 19,628-38,952) for stays > 14 days. Figure 3 shows the significant linear correlation between IS cost and LOS

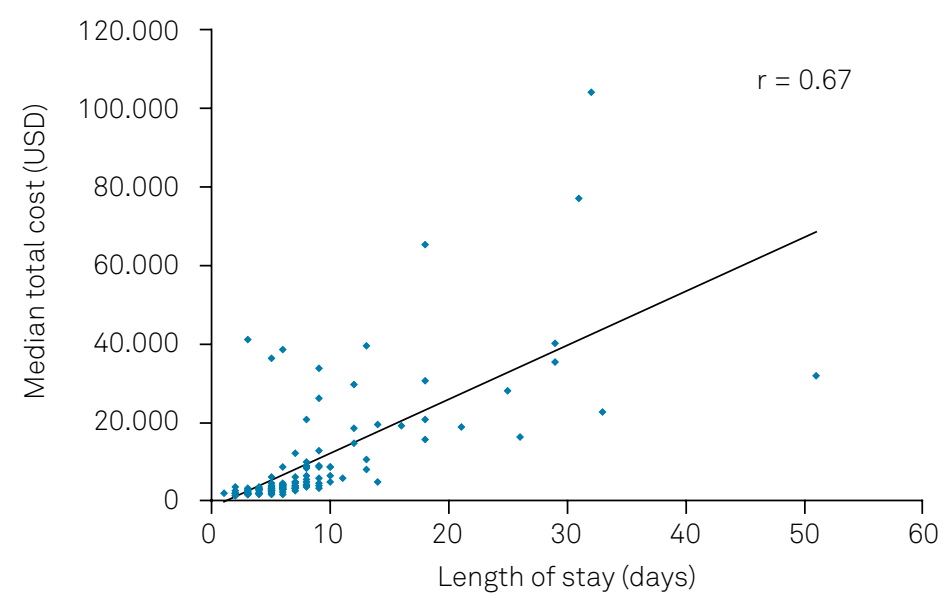

Figure 3. Ischemic stroke cost per length of stay.

Table 2. Total in-hospital cost and daily cost per patient among stroke types and TIA.

\begin{tabular}{lccccc}
\hline Variable & IS $(n=131)$ & PIH $(n=11)$ & SAH $(n=4)$ & TIA $(n=27)$ & $p$-value \\
\hline Median total cost (IQR) & $3,828(2,800-8,664)$ & $16,442(5,108-33,355)$ & $28,928(12,424-48,037)$ & $2,316(1,692-2,959)$ & $<0.0001$ \\
Mean total cost (SD) & $9,766(14,899)$ & $21,790(21,276)$ & $31,532(23,462)$ & $2,596(1,331)$ & $<0.0001$ \\
Median daily cost (IQR) & $691(540-1,016)$ & $1,297(624-2,171)$ & $2,115(1,670-2,977)$ & $623(530-766)$ & 0.0024 \\
Mean daily cost (SD) & $1,098(1,476)$ & $1,433(885)$ & $2,533(1,349)$ & $709(304)$ & $<0.0001$
\end{tabular}

TIA: transient ischemic attack; PIH: primary intracerebral hemorrhage; SAH: subarachnoid hemorrhage; IS: ischemic stroke. IQR: interquartile range; SD: standard deviation. All prices are in US $\$$ adjusted to the gross domestic product deflator index values and purchasing power parity ${ }^{13}$. 
$(\mathrm{r}=0.67 ; \mathrm{p}<0.001)$. Table 3 shows the cost per stroke type stratified by weeks of hospital stay.

Also as expected, the IS costs grew according to clinical severity when arriving at hospital (Figure 4). The costs were US\$3,370 (IQR: 2,418-4,718) for the 81 mild IS patients (NIHSS: 0-3), US\$4,335 (IQR: 3,297-8,599) for the 35 moderate
IS patients (NIHSS: 4-10) and US\$30,753 (IQR: 21,751-38,973) for the 15 severe IS patients (NIHSS: $>10 ; \mathrm{p}<0.0001$ ).

The IS cost was also stratified with and without reperfusion (Figure 5). Intra-arterial (IA) thrombectomy increased the cost of IS treatment 10-11-fold compared to IV thrombolysis $(\mathrm{p}<0.0001)$. A total of 117 IS patients did not

Table 3. Median cost per stroke type over time and mean LOS.

\begin{tabular}{lccccc} 
Variable & IS $(n=131)$ & PIH $(n=11)$ & SAH $(n=4)$ & TIA $(n=27)$ & $p$-value \\
\hline$<1$ week & $2,639(2,017-3,274)$ & $2,220^{*}$ & $\ldots$ & $2,238(1,653-2,652)$ & 0.33 \\
$1-2$ weeks & $4,743(3,609-8,687)$ & $7,924(5,108-20,088)$ & $13,081(11,760-35,452)$ & $3,486(3,385-4,336)$ & 0.0004 \\
$>2$ weeks & $29,499(19,628-38,952)$ & $37,895(33,789-54,624)$ & $44,775 *$ & $\ldots$. & 0.19 \\
LOS (days) & $8(7)$ & $15(16)$ & $11(5)$ & $4(2)$ & $<0.0001$
\end{tabular}

TIA: transient ischemic attack; PIH: primary intracerebral hemorrhage; SAH: subarachnoid hemorrhage; IS: ischemic stroke. LOS: length of stay. All values are given in US\$. LOS values in median and standard deviation. Costs were adjusted to gross domestic product deflator index values and purchasing power parity.13 *Available for one case.

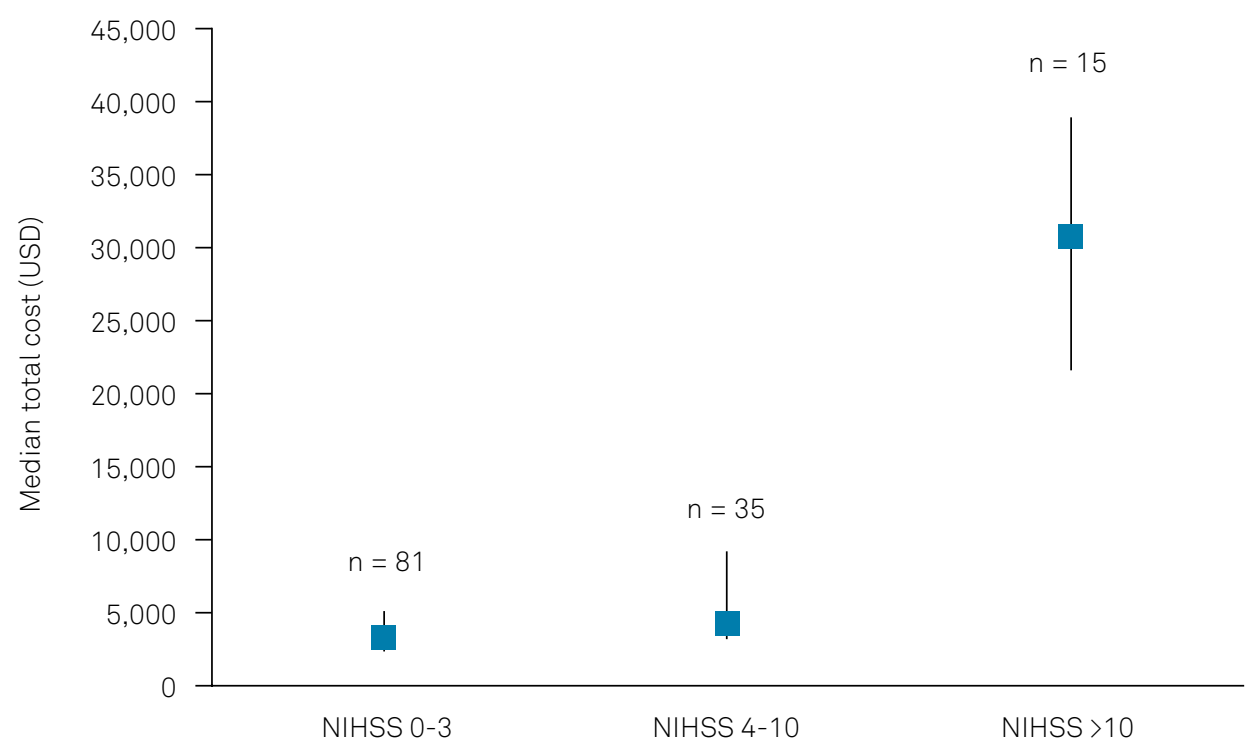

*The $y$-axis represents IQR values

Figure 4. Ischemic stroke cost per clinical severity (NIHSS).

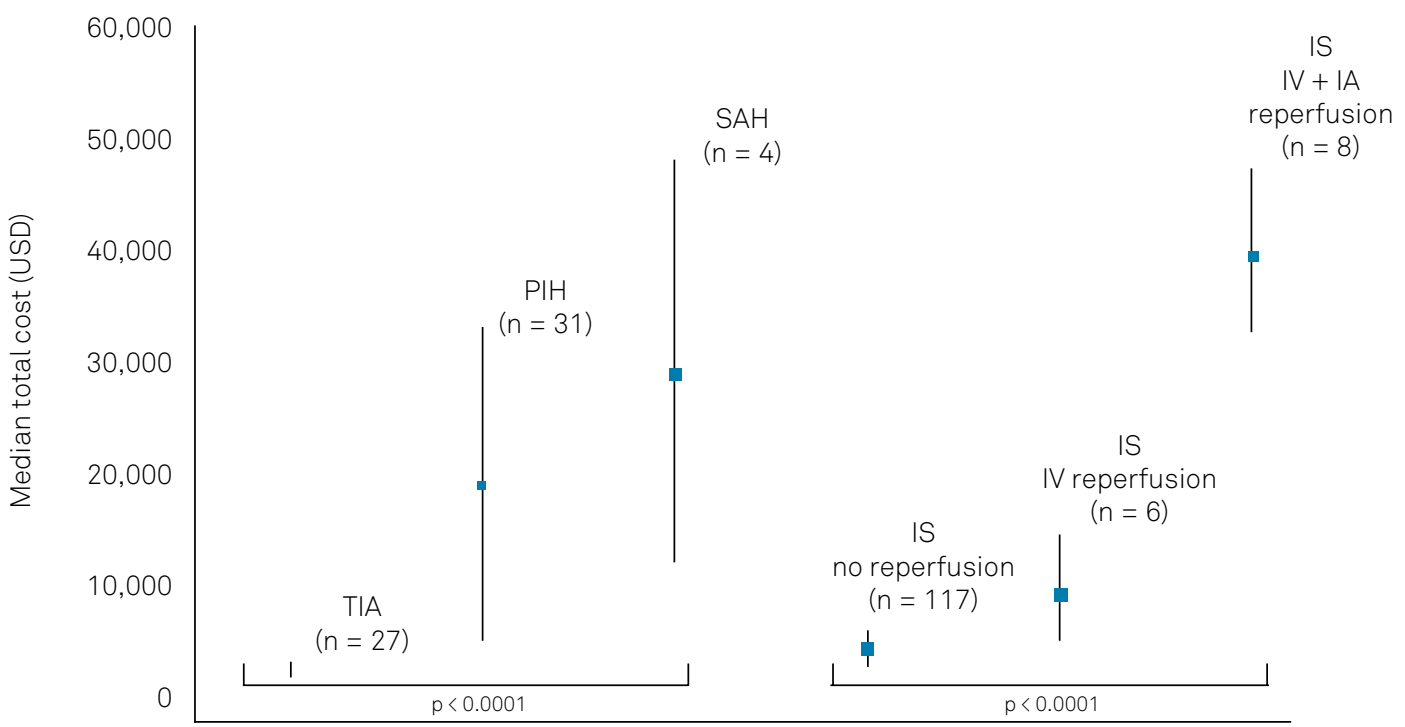

Figure 5. Costs of stroke in private hospitals, Joinville, Brazil. 


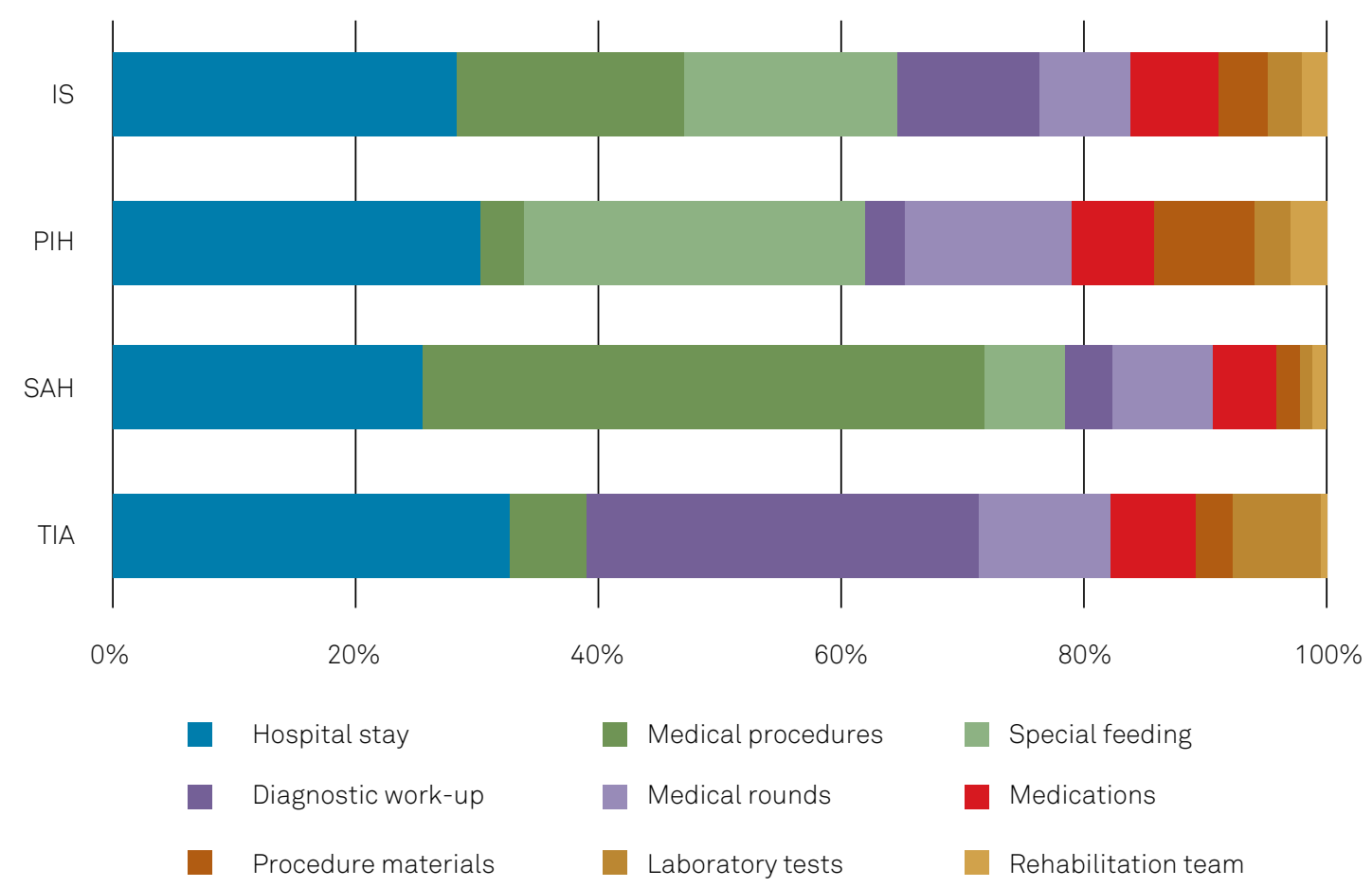

Figure 6. Composition of the hospital total cost per type of stroke.

receive cerebral reperfusion, and the median cost for each patient was US\$3,539 (IQR: 2,647-5,771). Conversely, six patients received IV thrombolysis, and the median cost each patient was US\$11,463 (IQR: 8,931-14,291). In addition, eight patients received IV thrombolysis and IA thrombectomy, and the median cost for each patient was US $\$ 37,948$ (IQR: 32,697-47,205).

The proportions of costs were calculated among all strokes types and TIA. These included daily costs, emergency room rates, medications, materials, laboratory investigations, medical procedures, medical fees, diagnostic work-ups, multidisciplinary teams, special nutrition, medical gases and administrative fees (Figure 6). Table 4 shows the unit costs of each item and the average cost per stroke type in 2016-2017.

Hospital stay had the greatest impact on total cost in IS, PIH and TIA (representing $24 \%$ to $32 \%$ of the total cost). Hospital stay costs for intensive care and nursing comprised $26 \%$ of all final bills (US $\$ 474,602$ to US $\$ 1,845,927$ ). In the SAH group, the greatest impact was from medical procedures (44\%). This was also the item with the second greatest impact on final cost in IS patients (18\%). These procedures comprised $15 \%$ of the total final bill (US $\$ 274,736 /$ US $\$ 1,845,927$ ). Intra-arterial thrombectomies (solitaire stent, for anterior circulation $8 \mathrm{~F}$ Corail balloon-guided catheter (Balt) and for posterior circulation $6 \mathrm{~F}$ Chaperon catheter) were performed in $6 \%$ of all patients $(8 / 131)$ and comprised $7 \%$ of the total final bill (US\$130,467/US\$1,845,927). Therefore, more than one-third of all medical and nonmedical costs were incurred by two items.

\section{DISCUSSION}

This prospective study in a middle-income country showed that the overall in-hospital cost of 173 strokes during 2016-17 was approximately US\$1.8 million. The average cost per patient was US\$10,404. As expected, IS was the most common type of stroke (76\%). The cost of IS treatment was greater in patients who had a more severe stroke and in those submitted to IV thrombolysis and IA thrombectomy. Overall, the IS costs were approximately US $\$ 3,500$ for those without cerebral reperfusion, US $\$ 11,500$ for those receiving IV thrombolysis and US $\$ 38,000$ for those receiving IV and IA cerebral reperfusion. To compare these findings, the values from the original studies were adjusted to the PPP for the GDP in 2016. Therefore, the median IS costs (without cerebral reperfusion) in this study were higher than in a public hospital in São Paulo in 2009 (US\$2,166) ${ }^{4}$ but lower than private costs in India (US $\$ 3,720$ ) in $2013^{14}$, Japan (US\$6,640) in $2003^{15}$ and the Netherlands in 2015 (US\$7,496) ${ }^{16}$. The costs for IV or combined cerebral reperfusion treatment for IS were similar to those of studies conducted in the USA; for instance, the median hospital costs for 63,472 IS patients who received IV thrombolysis from 2001 to 2008 in the USA was US\$15,751 (IQR: 11,155-23,253) ${ }^{17}$. Studies in the USA have recently reported even higher costs; for example, costs ranged from US $\$ 24,817$ to US $\$ 33,810$ for IV thrombolysis, and from US\$39,825 to US $\$ 40,743$ for IV and IA thrombolysis ${ }^{18}$. In the latter study, the clinical severity of patients submitted to IV thrombolysis was greater than 
Table 4. Unit costs and average composition of costs per stroke type.

\begin{tabular}{|c|c|c|c|c|c|}
\hline Item cost & $\begin{array}{l}\text { Unit } \\
\text { costs }\end{array}$ & $\begin{array}{c}\text { IS } \\
(n=131)\end{array}$ & $\begin{array}{c}\mathrm{PIH} \\
(n=11)\end{array}$ & $\begin{array}{l}\text { SAH } \\
(n=4)\end{array}$ & $\begin{array}{c}\text { TIA } \\
(n=27)\end{array}$ \\
\hline \multicolumn{6}{|l|}{ Hospital-stay } \\
\hline Nursering & 292 & 268,122 & 21,920 & 8,213 & 7,894 \\
\hline Intensive care days & 762 & 99,876 & 45,744 & 22,833 & $\ldots$ \\
\hline Medical rounds & 47 & 84,443 & 29,155 & 10,161 & 5,064 \\
\hline Emergency room rounds & 55 & 8,910 & 1,217 & 221 & 2,048 \\
\hline Emergency room rate & 30 & 3,898 & 327 & 119 & 803 \\
\hline Medical procedures* & 3,257 & 219,590 & 5,196 & 48,243 & 1,707 \\
\hline Thrombectomy IA & 16,308 & 130,467 & $\ldots$ & $\ldots$ & $\ldots$ \\
\hline Physical/Occupational therapy & 15 & 15,914 & 5,786 & 1,215 & 263 \\
\hline Speech therapy & 14 & 8,919 & 640 & 218 & 66 \\
\hline \multicolumn{6}{|l|}{ Diagnostic and imaging tests } \\
\hline CT (brain) & 163 & 5,714 & 1,796 & 653 & $\ldots$ \\
\hline Carotid ultrasound & 184 & 24,086 & $\ldots$ & $\ldots$ & 4,964 \\
\hline ECG & 15 & 1,985 & 170 & 371 & 417 \\
\hline X-ray (thorax/abdomen) & 22 & 872 & 131 & 698 & $\ldots$ \\
\hline MRI (brain) & 325 & 42,598 & 3,577 & 1,300 & 8,780 \\
\hline Angio MRI, Angio CT & 227 & 29,795 & $\ldots$ & 910 & 227 \\
\hline Transthoracic Echocardiogram & 149 & 19,523 & 1,639 & 595 & 4,024 \\
\hline Transcranial Doppler & 171 & 22,443 & $\ldots$ & $\ldots$ & 4,112 \\
\hline Arteriography & 2,611 & 13,057 & 2,611 & 7,834 & 2,611 \\
\hline Materials & 11 & 51,397 & 18,532 & 2,539 & 2,181 \\
\hline Laboratory tests ${ }^{\ddagger}$ & 13 & 32,724 & 6,508 & 1,052 & 4,970 \\
\hline Drugs & 8 & 52,640 & 11,207 & 4,234 & 4,729 \\
\hline rtPA Alteplase & 970 & 14,552 & $\ldots$ & $\ldots$ & $\ldots$ \\
\hline Antibiotics & 39 & 23,748 & 3,879 & 2,018 & $\ldots$ \\
\hline Special feeding ${ }^{\ominus}$ & 192 & 215,771 & 62,499 & 8,075 & $\ldots$ \\
\hline Medical gases & 31 & 30,604 & 16,960 & 4,684 & 31 \\
\hline Administrative fees & 22 & 2,944 & 244 & 90 & 430 \\
\hline Sub-total (all patients) & & $1,424,592$ & 239,738 & 126,276 & 55,321 \\
\hline
\end{tabular}

$\begin{array}{lr}\text { Total (all patients) } & 1,845,927\end{array}$

Unit costs (including medical and non-medical cost, see description in the methods) in means. *Medical procedures included all neurosurgical and neuroradiological plus other general medical procedures (gastrostomy, tracheostomy, endoscopic procedures). ‡Mean of all biochemistry, cytopathology and bacteriological exams. ${ }^{\ominus}$ Special feeding included enteral diet with materials necessary for the administration.

that in this study, whereas the patients receiving IA and IV reperfusion had clinical severities costs that were similar to those in this study.

As in other studies, LOS and clinical severity were directly related to the final hospital $\operatorname{costs}^{19,20}$. The LOS in this study was approximately 11 days for a major stroke and four days for a TIA. The LOS for IS (eight days) was shorter than for patients in Japan (33 days) $)^{15}$, China (20 days $)^{19}$ and Brazil (13 days) ${ }^{4}$ but similar to patients in the Netherlands $\left(\right.$ seven days) ${ }^{16}$ and Malaysia (six days) ${ }^{21}$. These differences were attributed to two main factors: 1 ) other studies with a higher $\operatorname{LOS}^{15,19}$ included patients with a higher clinical severity at hospital admission, and 2) the characteristics of the hospitals were different in China (secondary and tertiary hospitals); treatment of the acute and rehabilitation phase was performed in Japan; the other Brazilian study was carried out in a public hospital.

The median costs of PIH in this study was US $\$ 16,442$, which was higher than the costs reported in 2009 in São Paulo (US\$4,670) in public hospitals ${ }^{4}$. A cohort study in Canada reported that the median cost of hospital care for 987 PIH patients was US $\$ 11,777$ per patient ${ }^{22}$. The PIH costs in this study were higher than in Malaysia (US $\$ 3,012)^{21}$ and China (US\$4,934) ${ }^{19}$.

Subarachnoid hemorrhage was the most expensive of all stroke types. The median SAH cost in this study was US $\$ 28,928$, which was similar to Germany (US\$24,091) ${ }^{23}$ but lower than Singapore (US\$38,633) ${ }^{24}$. Again, all costs were lower than in the USA, where the median cost for hospitalization of clipped and coiled patients was US $\$ 77,462$ and US $\$ 74,041$, respectively, in 
$2008^{25}$. The sample of patients with SAH in this study was very small $(n=4)$, thus making it difficult to compare the results with those reported in the literature.

The median cost of a TIA in this study was US $\$ 2,316$ and the mean LOS was four days. In the Netherlands, the LOS was the same, but the costs were higher (US\$3,474) ${ }^{16}$. In the USA, the LOS was also the same but the costs were even higher (US\$16,450) ${ }^{26}$. In this USA study, the author reported that the treatment of TIA comorbidities, the characteristics of hospitals and health insurance increased the LOS and cost of hospitalization.

This study has some limitations. For example, the absence of a standard methodology for computing the costs of two hospital entities made it necessary to create a method for the appropriation and allocation of costs; the sample for SAH, PIH and TIA were small; the two general and private hospitals did not have stroke units; the hospitals cared for patients from 27 different health plans and variations were found in the price tables of the inputs and the profit of private entities was included in the final costs. The strength of this study includes its prospective design, which included all medical and nonmedical costs for all stroke types and TIAs from a private-sector setting. To compare the findings with costs in other private hospitals, the costs of the original studies were adjusted to the GDP Deflator Index and PPP in $2016^{13}$.

In conclusion, stroke is a costly disease that is directly associated with the length of hospital stay and clinical severity. The costs of PIH and SAH were more expensive than IS. When only hospital costs were considered, IV cerebral reperfusion for IS was three times more expensive than conservative treatments, whereas combined treatments were 11 times more expensive. The costs associated with greater stroke severity and disability in eligible IS patients not treated with reperfusion therapies were not calculated. In high-income countries, the cost-effectiveness of cerebral reperfusion for IS has been defined, ${ }^{27,28}$ however, in Brazil, only one retrospective study has shown that the use of thrombolysis in IS patients changes the natural history of the disease and, moreover, that the intervention contributes to the reduction of direct (hospitalization and rehabilitation) and indirect (loss of productivity) costs ${ }^{29}$. It is highly likely that thrombectomy is also cost-effective in developing countries.

\section{References}

1. Ovbiagele B, Goldstein LB, Higashida RT, Howard VJ, Johnston SC, Khavjou OA, et al.; American Heart Association Advocacy Coordinating Committee and Stroke Council. Forecasting the future of stroke in the United States: a policy statement from the American Heart Association and American Stroke Association. Stroke. 2013 Aug;44(8):2361-75. https://doi.org/10.1161/STR.0b013e31829734f2

2. Murray CJ, Vos T, Lozano R, Naghavi M, Flaxman AD, Michaud C, et al. Disability-adjusted life years (DALYS) for 291 diseases and injuries in 21 regions, 1990-2010: a systematic analysis for the Global Burden of Disease Study 2010. Lancet. 2012 Dec;380(9859):2197-223. https://doi.org/10.1016/S0140-6736(12)61689-4

3. Feigin VL, Forouzanfar MH, Krishnamurthi R, Mensah GA, Connor M, Bennett DA, et al.; Global Burden of Diseases, Injuries, and Risk Factors Study 2010 (GBD 2010) and the GBD Stroke Experts Group. Global and regional burden of stroke during 1990-2010: findings from the Global Burden of Disease Study 2010. Lancet. 2014 Jan;383(9913):245-54. https://doi.org/10.1016/S0140-6736(13)61953-4

4. Christensen MC, Valiente R, Sampaio Silva G, Lee WC, Dutcher S, Guimarães Rocha MS, et al. Acute treatment costs of stroke in Brazil. Neuroepidemiology. 2009;32(2):142-9. https://doi.org/10.1159/000184747

5. Cabral NL, Cougo-Pinto PT, Magalhaes PS, Longo AL, Moro CH, Amaral CH, et al. Trends of stroke incidence from 1995 to 2013 in Joinville, Brazil. Neuroepidemiology. 2016;46(4):273-81. https://doi.org/10.1159/000445060

6. Hill MD, Goyal M, Demchuk AM. Endovascular stroke therapy-a new era. Int J Stroke. 2015 Apr;10(3):278-9. https://doi.org/10.1111/ijs.12456

7. Paim J, Travassos C, Almeida C, Bahia L, Macinko J. The Brazilian health system: history, advances and challenges. Lancet. 2011 May;377(9779):1778-97. https://doi.org/10.1016/S0140-6736(11)60054-8

8. Evers SM, Struijs JN, Ament AJ, Genugten ML, Jager $\mathrm{JH}$, Bos GA. International comparison of stroke cost studies. Stroke. 2004 May;35(5):1209-15. https://doi.org/10.1161/01.STR.0000125860.48180.48
9. Oliveira-Filho J, Martins SC, Pontes-Neto OM, Longo A, Evaristo EF, Carvalho JJ, et al.. Guidelines for acute ischemic stroke treatment: part I. Arq Neuropsiquiatr. 2012 Aug;70(8):621-9. https://doi.org/10.1590/S0004-282X2012000800012

10. Martins SC, Freitas GR, Pontes-Neto OM, Pieri A, Moro CH, Jesus PA, et al. Guidelines for acute ischemic stroke treatment: part II: stroke treatment. Arq Neuropsiquiatr. 2012 Nov;70(11):885-93. https://doi.org/10.1590/S0004-282X2012001100012

11. Pontes-Neto OM, Oliveira-Filho J, Valiente R, Friedrich M, Pedreira B, Rodrigues BC, et al. [Brazilian guidelines for the manegement of intracerebral hemorrhage]. Arq Neuropsiquiatr. 2009 Sep;67 3B:940-50.Portuguese. https://doi.org/10.1590/S0004-282X2009000500034

12. Lyden P. Using the National Institutes of Health Stroke Scale: A Cautionary Tale. Stroke. 2017 Feb;48(2):513-9. https://doi.org/10.1161/STROKEAHA.116.015434

13. Shemilt I, Thomas J, Morciano M. A web-based tool for adjusting costs to a specific target currency and price year. Evid Policy. 2010;6(1):51-9. https://doi.org/10.1332/174426410X482999.

14. Kwatra G, Kaur P, Toor G, Badyal DK, Kaur R, Singh Y, et al. Cost of stroke from a tertiary center in northwest India. Neurol India. 2013 Nov-Dec;61(6):627-32. https://doi.org/10.4103/0028-3886.125270

15. Yoneda Y, Uehara T, Yamasaki H, Kita Y, Tabuchi M, Mori E. Hospital-based study of the care and cost of acute ischemic stroke in Japan. Stroke. 2003 Mar;34(3):718-24. https://doi.org/10.1161/01.STR.0000056171.55342.FF

16. Buisman LR, Tan SS, Nederkoorn PJ, Koudstaal PJ, Redekop WK. Hospital costs of ischemic stroke and TIA in the Netherlands. Neurology. 2015 Jun;84(22):2208-15. https://doi.org/10.1212/WNL.0000000000001635

17. Brinjikji W, Rabinstein AA, Cloft HJ. Hospitalization costs for acute ischemic stroke patients treated with intravenous thrombolysis in the United States are substantially higher than medicare payments. Stroke. 2012 Apr;43(4):1131-3. https://doi.org/10.1161/STROKEAHA.111.636142 
18. Rai AT, Boo S, Buseman C, Adcock AK, Tarabishy AR, Miller MM, et al. Intravenous thrombolysis before endovascular therapy for large vessel strokes can lead to significantly higher hospital costs without improving outcomes. J Neurointerv Surg. 2018 Jan;10(1):17-21. https://doi.org/10.1136/neurintsurg-2016-012830

19. Wei JW, Heeley EL, Jan S, Huang Y, Huang Q, Wang JG, et al. Variations and determinants of hospital costs for acute stroke in China. PLoS One. 2010 Sep;5(9):e13041. https://doi.org/10.1371/journal.pone.0013041

20. Asil T, Celik Y, Sut N, Celik AD, Balci K, Yilmaz A, et al. Cost of acute ischemic and hemorrhagic stroke in Turkey. Clin Neurol Neurosurg. 2011 Feb;113(2):111-4. https://doi.org/10.1016/j.clineuro.2010.09.014 PMID:21036465

21. Nor Azlin MN, Syed Aljunid SJ, Noor Azahz A, Amrizal MN, Saperi S. Direct medical cost of stroke: findings from a tertiary hospital in malaysia. Med J Malaysia. 2012 Oct;67(5):473-7.

22. Specogna AV, Patten SB, Turin TC, Hill MD. Cost of spontaneous intracerebral hemorrhage in Canada during 1 decade. Stroke. 2014 Jan;45(1):284-6. https://doi.org/10.1161/STROKEAHA.113.003276

23. Dodel R, Winter Y, Ringel F, Spottke A, Gharevi N, Müller I, et al. Cost of illness in subarachnoid hemorrhage: a German longitudinal study. Stroke. 2010 Dec;41(12):2918-23. https://doi.org/10.1161/STROKEAHA.110.586826

24. Venketasubramanian N, Yin A. Hospital costs for stroke care in Singapore. Cerebrovasc Dis. 2000 Jul-Aug;10(4):320-6. https://doi.org/10.1159/000016077
25. Brinjikji W, Kallmes DF, Lanzino G, Cloft HJ. Hospitalization costs for endovascular and surgical treatment of ruptured aneurysms in the United States are substantially higher than Medicare payments. AJNR Am J Neuroradiol. 2012 Jun;33(6):1037-40. https://doi.org/10.3174/ajnr.A2938

26. Qureshi Al, Adil MM, Zacharatos H, Suri MF. Factors associated with length of hospitalization in patients admitted with transient ischemic attack in United States. Stroke. 2013 Jun;44(6):1601-5. https://doi.org/10.1161/STROKEAHA.111.000590

27. Achit H, Soudant M, Hosseini K, Bannay A, Epstein J, Bracard S, et al. Cost-effectiveness of thrombectomy in patients with acute ischemic stroke: the THRACE randomized controlled trial. Stroke. 2017 Oct;48(10):2843-7. https://doi.org/10.1161/STROKEAHA.117.017856

28. Shireman TI, Wang K, Saver JL, Goyal M, Bonafé A, Diener HC, et al.; SWIFT-PRIME Investigators. Cost-effectiveness of solitaire stent retriever thrombectomy for acute ischemic stroke: results from the SWIFT-PRIME trial (solitaire with the intention for thrombectomy as primary endovascular treatment for acute ischemic stroke). Stroke. 2017 Feb;48(2):379-87. https://doi.org/10.1161/STROKEAHA.116.014735

29. Araújo DV, Teich V, Passos RB, Martins SC. Analysis of the cost-effectiveness of thrombolysis with alteplase in stroke. Arq Bras Cardiol. 2010;95(1):12-20. https://doi.org/10.1590/S0066-782X2010005000067 